\title{
Redox gateway associated with adventitious root formation under stress and hormonal signalling in plants
}

\author{
Durga Kora and Soumen Bhattacharjee* \\ Plant Physiology and Biochemistry Research Laboratory, Centre For Advanced Study, Department of Botany, University of Burdwan, \\ Burdwan 713 104, India
}

\begin{abstract}
This article highlights the physiological and molecular language that exploits redox pathways to modulate hormonal function and, transcriptional regulation of gene expression associated with adventitious root formation (ARF) in plants. The role of plant growth regulators that exploit the redox cue either by activating the NADPH-oxidase or modulating antioxidantcoupled redox signalling during ARF is also elaborated. We also elaborate upon various transcriptomic studies on the role of reactive oxygen species in upregulation of various proteins and transcription factors involved in cell cycle and cell division, hormone signalling, amino acid synthesis, protein processing, transport and cell-wall modification.
\end{abstract}

Keywords: Adventitious root formation, phytohormones, reactive oxygen species, redox cue, stress signalling.

THE root system of plants basically comprises primary, lateral and adventitious roots. The radical which is formed initially during embryogenesis, subsequently forms the primary root due to elongation. It either grows into thick central taproot system, which in most cases develops lateral secondary roots as in gymnosperms and dicotyledons, or it may die at the initial stage and is replaced by the fibrous root system that develops from the shoot tissue and is called adventitious roots (ARs), as in monocotyledons ${ }^{1}$. ARs always develop from differentiated cells in post-embryonic stage or tissues-like leaves and stems ${ }^{1,2}$. As ARs are formed naturally in monocotyledons as crown and brace roots, they also act as an adaptive strategy under various abiotic stresses, like mechanical injury or flooding ${ }^{3-6}$. Adventitious root formation (ARF) is central to the vegetative propagation of many economically significant plant species which are capable of developing ARs or develop them upon induction $^{7}$. In hypocotyls, ARs emerge from the cambium region (Figure 1). In addition to helping plants in water and nutrient uptake, storing of photo assimilates and anchoring to the substrate, ARs also help plants to adapt under

\footnotetext{
*For correspondence. (e-mail: sbhattacharjee@bot.buruniv.ac.in)
}

abiotic stress ${ }^{1,8}$. Strubińska and Hanaka ${ }^{9}$ have shown that the AR system is more tolerant to lead stress than the primary root system in the sunflower seedlings.

ARF is initiated through many signalling pathways. Several studies have indicated that reactive oxygen species (ROS) play important role in morphogenetic events like $\mathrm{ARF}^{10-12}$. The ROS and antioxidative defence system make up the elaborate redox system of a plant ${ }^{13}$. In fact, ROS-antioxidant interaction dynamics at metabolic interface is indispensable in maintaining cellular redox homeostasis. ROS as an obligate component, are derived from the incomplete reduction of molecular oxygen of eukaryotic organisms and comprise $\mathrm{O}_{2}^{--}, \mathrm{HO}^{\bullet}, \mathrm{H}_{2} \mathrm{O}_{2},{ }^{1} \mathrm{O}_{2}$, $\mathrm{RCO}^{\circ}, \mathrm{RO}^{\bullet}$, etc. ${ }^{10,13}$. The initial product of incomplete reduction, $\mathrm{O}_{2}^{--}$, is generated due to the single electronmediated reduction of molecular oxygen during metabolic dysfunction under stress. $\mathrm{O}_{2}^{\circ-}$ formed may get quickly dismutated by the enzyme superoxide dismutase (SOD) to form the most stable form of ROS, viz. $\mathrm{H}_{2} \mathrm{O}_{2}$ (ref. 13). Subsequently, $\mathrm{H}_{2} \mathrm{O}_{2}$ may be exploited further to generate superoxide radical to produce systemic signals. Under physiological condition, with the participation of transition metals like $\mathrm{Fe}^{2+}$ and $\mathrm{Cu}^{2+}, \mathrm{H}_{2} \mathrm{O}_{2}$ can be reduced

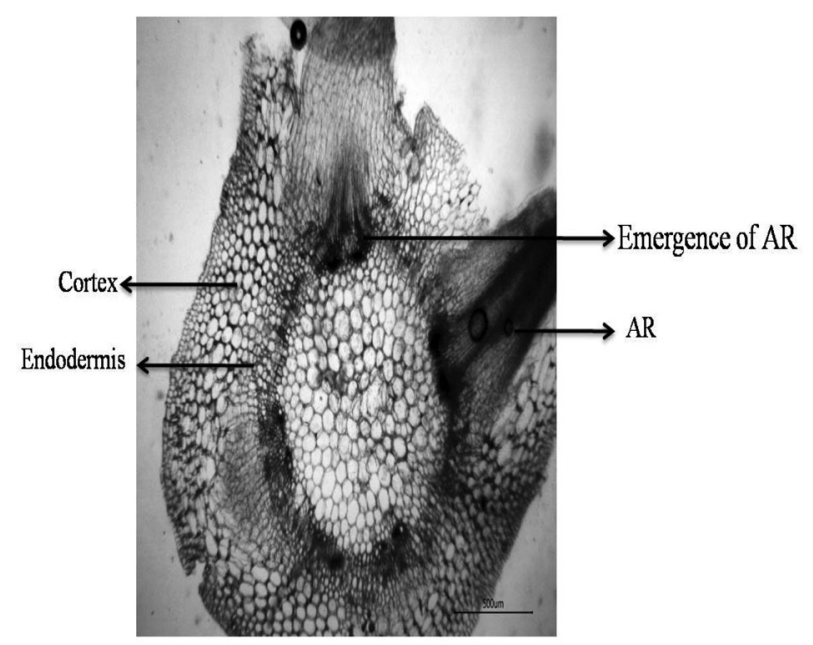

Figure 1. Transverse section of mung bean hypocotyl showing emergence of root primordial associated with adventitious root formation (ARF). 
further into the highly toxic and reactive hydroxyl radical $\left(\mathrm{HO}^{\bullet}\right)^{13}$. It is found that both exogenous (environmental stress) and endogenous (lack of metabolic coordination) causes contribute significantly to the formation of intracellular ROS, compared to the capacity of antioxidative defence system causing oxidative stress. Exogenous causes include extremes of temperature, irradiation or excess photochemical energy, salinity, drought, pollutants, chemicals and heavy metals. One of the prominent sources of ROS in the plant cell are the mitochondria, where ROS is generated by spilling of electrons from complex I and III to molecular oxygen during the electron-transport chain. Chloroplasts through pseudocyclic electron flow generate $\operatorname{ROS}^{10}$. Microbodies like peroxisomes and microsomes also generate $\operatorname{ROS}\left(\mathrm{H}_{2} \mathrm{O}_{2}\right)$ (ref. 10). The membrane-associated enzymes respiratory burst oxidase homologue $(\mathrm{RBOH})$ or NAD $(\mathrm{P}) \mathrm{H}$-oxidase, cytochrome- $c$ oxidase and xanthine oxidase are equally important in generating ROS in plant cells ${ }^{10}$. Plant $\mathrm{RBOH}$, essentially a homologue of gp $91^{\text {phox }}$ present as mammalian NADPH oxidase (NOX), contributes significantly in ROS-mediated apoptosis, signalling, stress acclimation, defence response and plant development ${ }^{13-16}$. In plants, the NOX homolog contains cytosolic NADPH and FADbinding domains with as many as six conserved transmembrane helices and distinctly possesses $\mathrm{N}$-terminus EF motifs, unlike the mammalian system. The third and fifth transmembrane helices attach two heme groups through His residues. Essentially, the heme groups are necessary for transport of electrons through the membrane to the extracellular electron-acceptor oxygen, to generate superoxide radical (ROS $)^{17}$. RBOH proteins are mostly localized in the plasmalemma membrane facing apoplast ${ }^{18-20}$. The presence of transition metal ions (redox-active metals) $\mathrm{Fe}$ and $\mathrm{Cu}$ also significantly accelerates ROS generation $^{10}$. Reduced forms of transition metal ions $\mathrm{Fe}(\mathrm{II})$ and $\mathrm{Fe}(\mathrm{III})$ generate highly reactive $\mathrm{HO}^{\circ}$, basically aiding Fenton reaction or Haber-Weiss reaction ${ }^{13,21}$.

Catalase detoxifies hydrogen peroxide, which is implicated in redox signalling and apoptosis. Other nonenzymatic anti-oxidants like vitamin $\mathrm{C}$ (ascorbic acid), flavanoids, $\alpha$-tocopherol and sulphur-containing antioxidants like glutathione, cysteine, etc. remove $\operatorname{ROS}^{13}$. The Halliwell-Asade pathway actively operates to remove $\mathrm{H}_{2} \mathrm{O}_{2}$ from the cells under oxidative stress. Under a certain set of environmental conditions, plants seem to produce ROS decisively and intentionally as internal redox cue or signalling molecules to regulate physiological events, including stomatal conductance, acclimatory stress response and defence, programmed cell death and morphogenesis ${ }^{21}$. ROS act as a 'second messenger' and modulate activities of specific regulatory proteins, transcription factors and gene expressions involved in specific signalling pathways ${ }^{13,21}$. Under physiological conditions, cells maintain redox homeostasis through regulation of ROS-antioxidant interaction dynamics, whereas under environmental stress the internal ROS titre is modulated either by increased production or changes in the efficacy of antioxidant defence system, thus originating nascent redox signal ${ }^{7,22}$. ROS, particularly $\mathrm{H}_{2} \mathrm{O}_{2}$ have been found to participate decisively in the morphogenetic process of $\mathrm{ARF}^{11,12}$. They act downstream of many hormones (like IAA, indole-3-butyric acid (IBA), ethylene, etc.) and plant growth promoters (like salicylic acid). ROS have been found to accumulate in the cambium of cucumber seedlings ${ }^{23}$. The participation of ROS in redox signalling during ARF necessitates a coordinated function of regulation of ROS-antioxidant interaction dynamics to maintain and regulate them at non-toxic titre ${ }^{12}$. A delicate harmonizing act between the genesis of ROS, involving ROSgenerating enzymes RBOH, and the basic cellular metabolism with ROS-scavenging pathways is significant for initiating the redox signal during ARF. This article highlights findings that support the major role of ROS or associated redox pathways in ARF, which could help to study the involvement of ROS in morphogenesis.

\section{Impact of environmental stress and phytohormone-induced modulation}

Oxidative burst is a universal intrinsic response of plants to environmental stress ${ }^{10}$. Plants acclimatize to unfavourable conditions by various morphological and anatomical changes brought about by various signalling pathways. The involvement of ROS in the signal transduction pathway is mainly produced by $\mathrm{NAD}(\mathrm{P}) \mathrm{H}$-oxidase associated with the plasma membrane. Unfavourable environmental conditions, like floods cause hypoxic condition to the submerged tissues ${ }^{3}$. Likewise, drought conditions limit water availability to the plants. One of the common morphological changes induced by both flood and drought is the formation of adventitious roots for proper gaseous exchange, sufficient water and nutrient uptake.

\section{Ethylene-induced alteration of redox homeostasis}

Stress hormone ethylene that accumulates in all flooded plant cells is known to enhance superoxide anion $\left(\mathrm{O}_{2}^{--}\right)$ formation by membrane-bound $\mathrm{NAD}(\mathrm{P}) \mathrm{H}$-oxidase ${ }^{24}$. The $\mathrm{O}_{2}^{\bullet-}$ formed is subsequently dismutated to $\mathrm{H}_{2} \mathrm{O}_{2}$ (refs 24 , 25). The enhanced level of endogenous reactive oxygen species, especially $\mathrm{H}_{2} \mathrm{O}_{2}$, shows increased root growth in adult rice plants during floods. The involvement of $\mathrm{H}_{2} \mathrm{O}_{2}$ in root growth is reduced when $\mathrm{RBOH}$ activity is inhibited $^{24}$. The activities of RBOH are largely controlled and synchronized by small G-proteins, Rac-GTPase and RopGTPase $^{26-28}$

Oxidative burst leading to enhanced concentration of $\mathrm{H}_{2} \mathrm{O}_{2}$ has also been shown to be indispensable for induction of adventitious roots in marigold under drought condition $^{29}$. It has already been mentioned that ethylene 


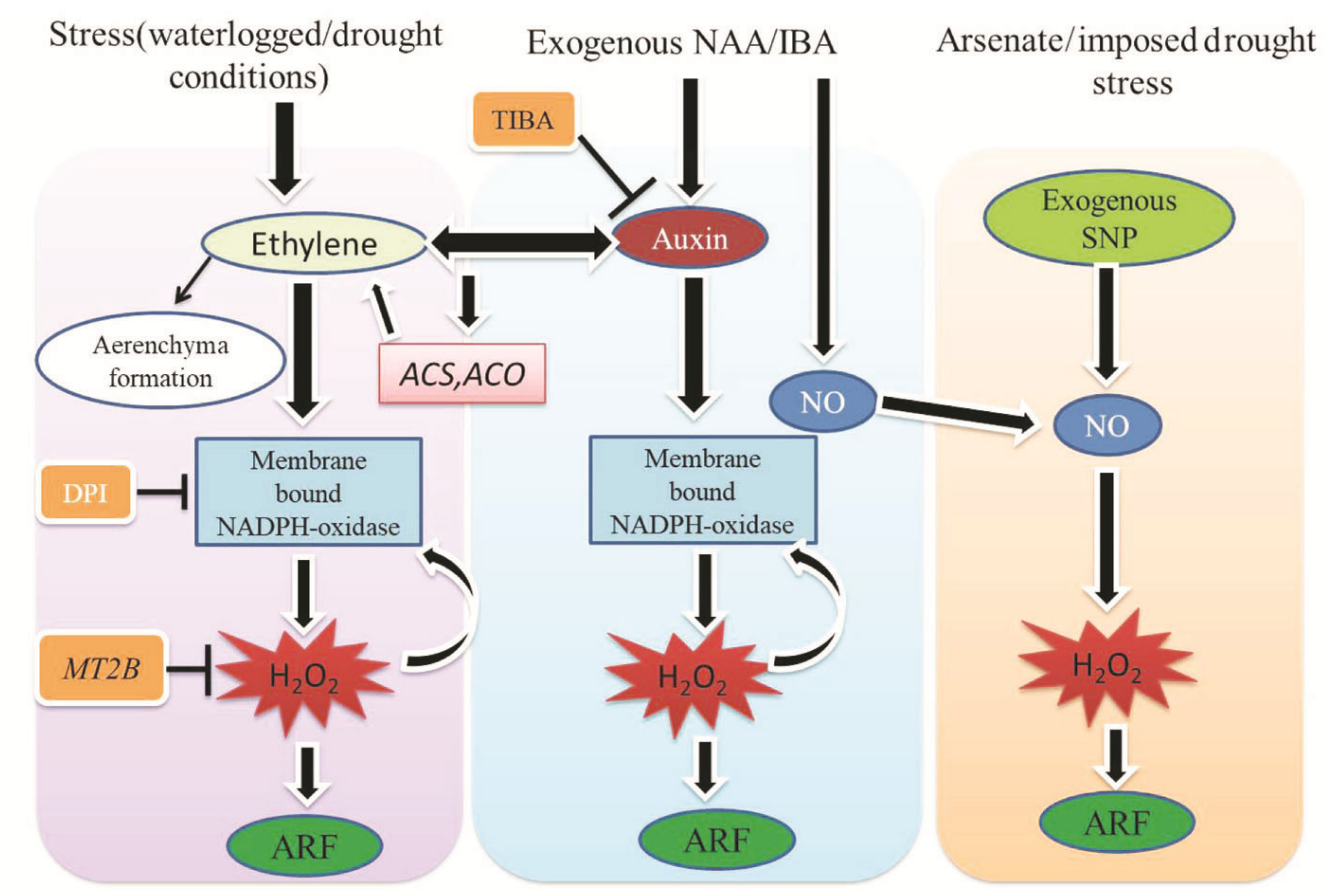

Figure 2. Ethylene, auxin and nitric oxide-induced ARF during different abiotic stresses. The plant growth regulators (PGRs) were found to crosstalk and activate the membrane-bound NAD(P)H-oxidase enzyme that helps in generating redox cue $\left(\mathrm{H}_{2} \mathrm{O}_{2}\right)$.

induces ARF and arenchyma formation via enhancement of the concentration of superoxide anion in adult rice (Oryza sativa) plants $^{28}$. Studies have revealed that $\mathrm{RBOH}$ acts downstream of ethylene in promoting root growth and epidermal cell death ${ }^{24}$. Epidermal cells that cover the primordia of adventitious roots at the stem node of rice plants undergo senescence to facilitate root emergence $^{24,30}$. It has been found that inhibition application of ethylene biosynthesis inhibitor, 1-methylcyclopropene (1-MCP) hardly affects $\mathrm{H}_{2} \mathrm{O}_{2}$-induced elevated rate of senescence, suggesting that senescence of epidermal cells triggered by ethylene is mainly mediated by $\mathrm{H}_{2} \mathrm{O}_{2}$ (ref. 31). Also, ethylene biosynthesis is regulated by both ethylene and $\mathrm{H}_{2} \mathrm{O}_{2}$ by feedback activation ${ }^{31}$. It was found that ACC Oxidase1 (ACO1; Os03g0860600) was upregulated, whereas Ethylene Overproducer-Like1 (EOL1; Os11g0585900, that targets ACS proteins) was inhibited particularly in the epidermal cells capping roots under the exposure of ethylene or $\mathrm{H}_{2} \mathrm{O}_{2}$ (ref. 31). Application of $1 \mu \mathrm{M}$ DPI (diphenyleneiodonium) and potassium iodide (KI) partially inhibited ethylene-induced ARF, suggesting the role of ROS downstream of the signalling network. DPI was also found to inhibit pressure-induced cell death. Further, down-regulation of $M T 2 b$ (ROS scavenger METALLOTHIONEIN2b) altered redox homeostasis, thus promoting cell death ${ }^{24,28,32,33}$, and supporting the fact that the induction of growth of root primorida by ROS is independent of $M T 2 b$ (ref. 24) (Figure 2). It was also reported that genetic down-regulation of $M T 2 b$ resulted in enhanced ROS $\left(\mathrm{H}_{2} \mathrm{O}_{2}\right)$ titre in suspension cultured rice cells. In fact, $\mathrm{H}_{2} \mathrm{O}_{2}$ itself mediates down-regulation of $M T 2 b$ in these epidermal cells, revealing a feedback loop that auto amplifies $\mathrm{H}_{2} \mathrm{O}_{2}$ accumulation ${ }^{34}$.

\section{Nitric oxide modulated redox homeostasis}

$\mathrm{H}_{2} \mathrm{O}_{2}$ interacts with various molecules that are generated during biotic and abiotic stress conditions. One such molecule is nitric oxide (NO). When drought condition was imposed on marigold explants by the application of polyethylene glycol (PEG), both the biomass and the number of adventitious roots were found to decrease after removal of primary roots compared to control (distilled water). However, $600 \mu \mathrm{M}$ of $\mathrm{H}_{2} \mathrm{O}_{2}$ or 5,10 and $50 \mu \mathrm{M}$ of sodium nitroprusside (SNP) increased both the biomass and the number of adventitious roots respectively, under drought conditions, similar to control treatment. When marigold explants were treated with PEG, SNP and DPI simultaneously, the positive effect of NO was reversed, again revealing that $\mathrm{H}_{2} \mathrm{O}_{2}$ acts downstream of $\mathrm{NO}$ signalling in ARF. The positive effect of $\mathrm{H}_{2} \mathrm{O}_{2}$ was found to be dose-dependent. Lower concentration did not form adventitious roots, whereas higher concentration inhibited the formation of $\mathrm{AR}^{29}$. Application of synthetic auxin, indole-3-butyric acid increased the endogenous concentration of both $\mathrm{NO}$ and $\mathrm{H}_{2} \mathrm{O}_{2}$ in marigold explants, suggesting that they are a prerequisite for ARF. When 
IBA and $\mathrm{H}_{2} \mathrm{O}_{2}$ were applied together, there was noteworthy enhancement in $\mathrm{ARF}^{35}$ (Figure 2).

A similar result has been found in ground-cover chrysanthemum, where exogenous application of $50 \mu \mathrm{M}$ SNP (NO donor) or $200 \mu \mathrm{M} \mathrm{H}_{2} \mathrm{O}_{2}$ was found to enhance ARF. When both were applied together, better results were observed than when applied alone ${ }^{36}$. It might be concluded that nitric oxide acts downstream of auxin that activates $\mathrm{NAD}(\mathrm{P}) \mathrm{H}$-oxidase resulting in the significant accrual of $\mathrm{O}_{2}^{\bullet-}$, thus helping in $\mathrm{ARF}^{37}$. This was cross-checked by the application of DPI and PTIO (2-phenyl-4,4,5,5-tetramethylimidazoline-1-oxyl3-oxide) that caused reduction in ARF in Panax ginseng. It has been shown that under arsenate stress, application of SNP (NO producers) enhances new ARF as well as primary root biomass ${ }^{38}$. When DPI was used, there was inhibition in new ARF, even in the presence of SNP, indicating that cell-cycle dynamics is controlled by NO and ROS. Further, it has been reported that elevated titre of redox couple ascorbate/dehydroascorbate is necessary for new ARF and the accumulation of primary root biomass ${ }^{38}$.

\section{ABA-induced modulation of redox homeostasis}

$\mathrm{H}_{2} \mathrm{O}_{2}$ has also been shown to act downstream in droughtinduced ABA-mediated ARF in Cucumis sativus. Exogenous ABA or $\mathrm{H}_{2} \mathrm{O}_{2}$ reversed the reduction in ARF caused by dehydration stress (PEG treatment). Best results were observed at $0.5 \mu \mathrm{M}$ ABA or $200 \mu \mathrm{M} \mathrm{H}_{2} \mathrm{O}_{2}$, matching the control treatment (distilled water), further suggesting that positive response of $\mathrm{H}_{2} \mathrm{O}_{2}$ and $\mathrm{ABA}$ is dose-dependent. The root-promoting effect of $\mathrm{ABA}$ was suppressed by the treatment of NAD(P)H-oxidase inhibitor, DPI (ref. 39). Cell-division activity was more pronounced in $\mathrm{PEG}+\mathrm{ABA}, \quad \mathrm{PEG}+\mathrm{H}_{2} \mathrm{O}_{2}$ and $\mathrm{PEG}+$ $\mathrm{H}_{2} \mathrm{O}_{2}+$ ABA compared to control, and PEG + DPI or PEG + CAT showed less pronounced ARF after staining with DAPI (4',6-diamidino-2-phenylindole), indicating that $\mathrm{H}_{2} \mathrm{O}_{2}$ could be important for ARF. ABA-mediated $\mathrm{H}_{2} \mathrm{O}_{2}$ production also increased water-soluble proteins under drought stress (Figure 3$)^{39}$.

\section{Auxin-induced modulation of redox homeostasis}

It is well-known that growth regulator auxins promote ARF with $\mathrm{H}_{2} \mathrm{O}_{2}$ as the second messenger ${ }^{11}$. The auxinethylene cross talk enhances ARF during stress conditions. Application of an inhibitor of auxin polar transport TIBA (2,3,5-triiodobenzoic acid) inhibits the formation of AR, which can also be partially rescued by treatment with $\mathrm{H}_{2} \mathrm{O}_{2}$ (Figure 2). Experimental evidences show that application of IBA increases $\mathrm{H}_{2} \mathrm{O}_{2}$ production ${ }^{11}$, suggesting possible cross talk between auxin and ROS signalling. It has also been shown that incubation with water for $12-36 \mathrm{~h}$ after cutting the primary roots enhances endogenous $\mathrm{H}_{2} \mathrm{O}_{2}$ level in mung bean seedlings, whereas in IBA-treated seedlings the internal titre of $\mathrm{H}_{2} \mathrm{O}_{2}$ increases after $3 \mathrm{~h}$ of primary root removal ${ }^{11}$. The importance of both nitric oxide and hydrogen peroxide in the promotion of ARF in explants of marigold (Tagetes erecta L.) is well known in the literature. IBA has been shown to increase endogenous concentration of both NO and $\mathrm{H}_{2} \mathrm{O}_{2}$ in marigold explants, suggesting that they are a prerequisite for $\mathrm{ARF}^{35}$. When IBA and $\mathrm{H}_{2} \mathrm{O}_{2}$ were applied together, there was significant increase in $\mathrm{ARF}^{35}$.

In another study on cucumber, cross talk between ROS and hormones like auxin and ethylene led to increased ARF under waterlogged condition. The expression of genes of important enzymes of ethylene biosynthesis, 1aminocyclopropane-1-carboxylate synthase (ACS) that converts $S$-adenosylmethionine to 1 -aminocyclopropane1-carboxylic acid (ACC) and 1-aminocyclopropane-1carboxylate oxidase (ACO) that converts ACC to ethylene in cucumber (CsACS1, CsACS2, CsACO2 and CsA$C O 5)$, were found to be enhanced under waterlogging condition and their expressions were upregulated by further application of NAA (synthetic auxin, 1-naphthylacetic acid) ${ }^{23}$ (Figure 2). Among the nine genes of respiratory burst oxidative homolog, responsible for generating $\mathrm{O}_{2}^{\bullet-}, C s R B O H$ was found to be upregulated by exogenous $\mathrm{NAA}^{23}$. Further, NAA and ACS both upregulated the expression of two $C s R B O H$ s, i.e. $C s R B O H B$ and CsRBOHF3 (Figure 2). Exogenous application of $\mathrm{H}_{2} \mathrm{O}_{2}$ did not affect the concentration of ethylene or auxin, but the application of DPI inhibited ethylene-auxin-induced AR, suggesting that ROS act downstream of these hormones in this development process ${ }^{23}$. It was also found that $100 \mu \mathrm{M} \mathrm{H}_{2} \mathrm{O}_{2}$ positively enhanced adventitious rooting in flax seeds, when combined with $0.5 \mathrm{mg} \mathrm{l}^{-1}$

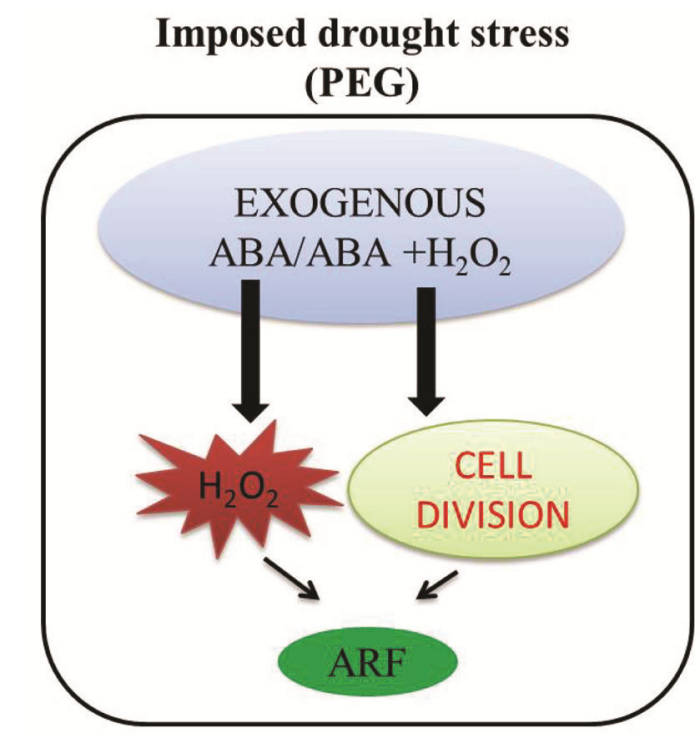

Figure 3. Role of exogenous application of abscisic acid in the induction of cell division necessary for ARF. 


\section{REVIEW ARTICLES}

NAA compared to NAA alone. Here, the endogenous $\mathrm{H}_{2} \mathrm{O}_{2}$ is controlled by peroxidase, which in turn regulates the endogenous auxin level in flax (Linum usitatissimum $)^{40}$.

In another study on cucumber, it was found that IAA, IBA, hemin, $\mathrm{SNP}, \mathrm{CaCl}_{2}$ and $\mathrm{NaHS}$ showed simultaneous increase in ARF, and differential upregulation in CsHOI (heme oxygenase-1 gene, which gives rise to $\mathrm{CO}$ ) and corresponding protein levels ${ }^{41}$ (Figure 4).

\section{SA-induced redox modulation}

ROS especially $\mathrm{H}_{2} \mathrm{O}_{2}$ are found to act downstream in SAinduced $\mathrm{ARF}^{12,42}$. Application of $\mathrm{H}_{2} \mathrm{O}_{2}$ scavenger DMTU (N,N'-dimethylthiourea) reduced $\mathrm{SA}$-induced ARF from hypocotyl explants of mung bean ${ }^{12}$. Similarly, application of DPI to the mung bean hypocotyl, significantly downregulated the formation of $\mathrm{AR}$ triggered by $\mathrm{SA}$ treatment ${ }^{12}$. In vivo $\mathrm{H}_{2} \mathrm{O}_{2}$ content was found to be increased at $12 \mathrm{~h}$ after SA incubation of the explants. The results of endogenous $\mathrm{H}_{2} \mathrm{O}_{2}$ assay further indicate increased accumulation $\mathrm{H}_{2} \mathrm{O}_{2}$ in $\mathrm{SA}$-treated seedlings compared to control, indicating that the SA-induced accrual of endogenous titre of $\mathrm{H}_{2} \mathrm{O}_{2}$ might be a downstream event during the entire signalling episode regulating ARF in mung bean seedlings ${ }^{12}$. Moreover, redox modulation of hypocotyl of mung bean by pre-treatment with $\mathrm{H}_{2} \mathrm{O}_{2}(10 \mathrm{mM})$ followed by SA $(0.4 \mathrm{mM})$ treatment resulted in upregulation of ARF, as verified by the enhanced root number and biomass, vis-à-vis hypocotyls treated individually with $\mathrm{H}_{2} \mathrm{O}_{2}$ or $\mathrm{SA}^{12}$. SOD activity was also found to increase significantly compared to CAT under the same treatment conditions, suggesting that enhancement in endogenous

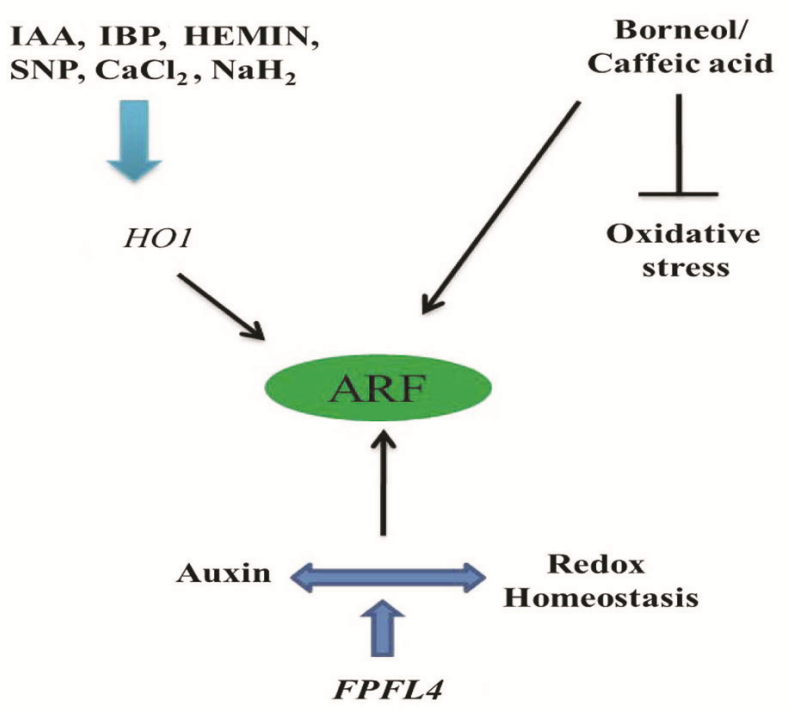

Figure 4. Burneol, FPLF4 (flower promoting factor), HOl (heme oxygenase-1 gene) induce ARF whereas caffeic acid inhibit ARF by inducing oxidative stress. titre of $\mathrm{H}_{2} \mathrm{O}_{2}$ under SA treatment is an outcome of antioxidant-coupled redox modulation that up- and downregulates SOD and CAT activities respectively. Further, an experiment with SA induction-deficient mutants eds51 and $e d s 5-2$ showed lower ARF than wild type ${ }^{33,42-44}$. In a recent study, it has been shown that treatment with $500 \mu \mathrm{M} \mathrm{H}_{2} \mathrm{O}_{2}$ in combination with $600 \mu \mathrm{M}$ SA to the hypocotyl explants of mung bean exhibited upregulation in ARF compared to untreated control ${ }^{12}$. The same was found to be significantly lesser in $1 \mathrm{mM}$ DMTU-600 $\mu \mathrm{M}$ SA and $1 \mathrm{mM}$ DPI- $600 \mu \mathrm{M}$ SA treated explants. Assessment of internal redox status of the experimental hypocotyl explants under such treating conditions were evaluated and compared. The prooxidant/antioxidant ratio, in situ ROS localization, changes in total thiol content, antioxidant capacity and efficacy of ascorbateglutathione system, revealed major modification of ROS-antioxidant interaction dynamics (Figure 5). The pro-oxidants measured in terms of $\mathrm{O}_{2}^{--}$activity, endogenous $\mathrm{H}_{2} \mathrm{O}_{2}$ estimation and total ROS estimation using DCFDA showed higher accumulation in $\mathrm{H}_{2} \mathrm{O}_{2}-\mathrm{SA}$ treated explants compared to control, DMTU-SA and DPI-SA treated explants, whereas activity of catalase, ascorbate peroxidase, dehydroascorbate reductase and glutathione reductase was found to be lower in $\mathrm{H}_{2} \mathrm{O}_{2}-\mathrm{SA}$ treated explants, establishing close association between SA and $\mathrm{H}_{2} \mathrm{O}_{2}$ in generating an oxidative burst linked with $A R F^{12}$. Comparative estimation of soluble components of the ascorbate-glutathione pathway along with their redox turnover dynamics from differently redox-modulated and SA-treated hypocotyl explants of mung bean also validates the metabolic basis of oxidative burst in terms of $\mathrm{H}_{2} \mathrm{O}_{2}$ accumulation, associated with $\mathrm{ARF}^{12}$. Further, gene

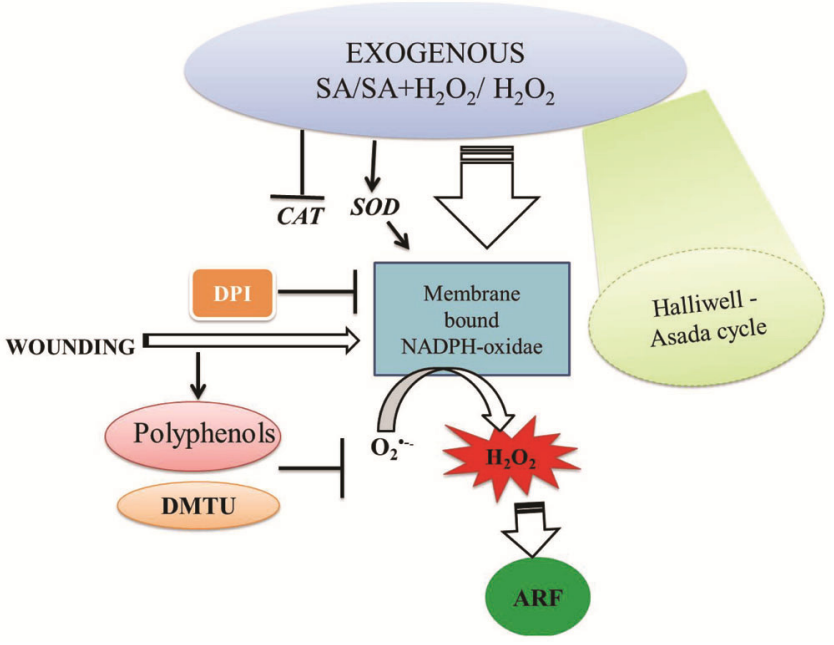

Figure 5. Role of exogenously applied $\mathrm{H}_{2} \mathrm{O}_{2}$ and salicylic acid that activate $\mathrm{NAD}(\mathrm{P}) \mathrm{H}$-oxidase and subsequently control the HalliwellAsada pathway for accumulation of endogenos redox cue necessary for ARF. Wounding also causes accumulation of reactive oxygen species (ROS), and stimulates formation of phenol compound that checks ROS, indicating its role in ARF. 
expression studies (semiquantitive RT-PCR and qRTPCR analysis) in terms of transcript abundance of the genes of important redox regulatory enzymes such as NAD(P)H-oxidase $(\mathrm{RBOH})$, catalase (CAT), ascorbate peroxidase (APOX), dehydroascorbate reductase (DHAR) and glutathione reductase (GR) from different redoxmodulated and SA-treated hypocotyl explants of mung clearly exhibited redox regulation of $\mathrm{ARF}^{12}$. The transcript abundances of vrrboh and $v r S O D$ genes were found to be significantly higher in the $\mathrm{H}_{2} \mathrm{O}_{2}-\mathrm{SA}$ combination in comparison to their untreated control, whereas DMTUSA and DPI-SA treatment conditions reduced transcript levels of both the enzymes over their control, corroborating strongly the redox regulation of $\mathrm{ARF}^{12}$. On the contrary, the expression of $v r C A T, v r A P X$ and $v r G R$ genes was found to be reduced in the hypocotyl explants of mung bean treated with $\mathrm{H}_{2} \mathrm{O}_{2}-\mathrm{SA}$, corroborating once again the role of antioxidant coupled redox event during $\mathrm{ARF}^{12}$.

\section{Wound-induced adventitious root formation and redox implications}

ARF-induced by wound or physical damage, i.e. cutting at the base of the stem, is the basis of vegetative propagation of numerous important plant species worldwide. As ROS come to play in response to any environmental stress, cutting at the base of stem deprives a plant or seedling from nutrients and water uptake, thus generating unfavourable conditions. To combat this, the plant produces or enhances the level of $\operatorname{ROS}^{45}$. Some studies have reported the role of $\mathrm{H}_{2} \mathrm{O}_{2}$ as the second messenger in wound response $\mathrm{w}^{32,46,47}$. So, removal of primary roots that eventually induce a wound signal might upregulate ARF which is necessary for the uptake of water and nutrients from the surroundings $\mathrm{s}^{3,11,12,36,48-50}$. Plant polyphenolic compounds are also found to increase in response to wounding and help protect from oxidative damage, indirectly corroborating ROS increment in response to wounding $^{51}$ (Figure 5).

There are several experimental evidences in support of the involvement of growth regulators, which either alone or synergistically through feed-forward and feed backward interactions can influence the redox status of the tissue, necessary for the formation of internal redox cue associated with ARF.

\section{Caffeic acid, borneol and flower promoting factor-based adventitious rooting}

Caffeic acid (CA) has been shown to inhibit ARF by inducing oxidative stress ${ }^{52}$. Different concentrations of CA have been shown to augment membrane lipid peroxidation (as revealed by the accumulation of thiobarbituric acid reactive substances), causing accumulation of ROS and oxidative damage in hypcotyl region of lower rooted mung $^{52}$. In another study it has been found that borneol, a bicyclic organic compound and a monoterpene, promotes adventitous rooting by acting as an antioxidant agent that removes wound-induced oxidative stress in Artemisia an$n u a^{53}$. It has also been found that OsFPFL4, a novel rice flower promoting factor is implicated in root and flower development in rice by regulating both auxin signalling and redox homeostasis ${ }^{54}$. The OSFPFL4 overexpression lines showed slightly greater ROS accumulation and more free IAA then the wild type and mutant, and there was cross talk between auxin and redox homeostasis ${ }^{54}$ (Figure 4).

\section{Redox regulation of adventitious root formation}

Exogenous application of $\mathrm{H}_{2} \mathrm{O}_{2}$ and inhibitors of $\mathrm{NAD}(\mathrm{P}) \mathrm{H}$-oxidase and free radical scavenger has shown that ARF can also be initiated by modulating the redox status of plant cells ${ }^{11,12}$. When endogenous $\mathrm{H}_{2} \mathrm{O}_{2}$ generation was reduced by DPI $(1,5$ and $10 \mathrm{mM})$ treatment, the biomass and the number of adventitious roots were significantly reduced $(P<0.05)$ and ARF was repressed entirely by treatment with NAD(P)H-oxidase inhibitor $(20 \mathrm{mM}$ DPI) in mung bean seedlings ${ }^{11}$. When different concentrations of DPI ( 1 or $5 \mathrm{mM}$ ) were used along with $\mathrm{H}_{2} \mathrm{O}_{2}$ ( $30 \mathrm{mM}$ ), the effects of $\mathrm{H}_{2} \mathrm{O}_{2}$ were reversed by DPI. On the other hand, the inhibitory effect of DPI on ARF could be reversed to a certain extent by the exogenous treatment of $\mathrm{H}_{2} \mathrm{O}_{2}$ (refs 11,12 ). These results confirm that ARF depends on the availability of pro-oxidant $\mathrm{H}_{2} \mathrm{O}_{2}$, and the mitigation of such events through application of inhibitor of $\mathrm{H}_{2} \mathrm{O}_{2}$-generating enzymes (DPI) retards ARF and growth ${ }^{11}$.

In an experiment using cucumber, incubation of hypocotyl explants after removal of primary root showed biphasic peaks of $\mathrm{H}_{2} \mathrm{O}_{2}$ generation (after 3 and $17 \mathrm{~h}$ of root removal $)^{10}$. On the contrary, application of DPI $(10 \mathrm{mM})$ to the explants after removal of primary root showed a rapid fall in $\mathrm{H}_{2} \mathrm{O}_{2}$ generation (within an hour), followed by slight increment (after $5 \mathrm{~h}$ ), and subsequently a permanent reduction. The experiment confirms the role of NAD $(\mathrm{P}) \mathrm{H}$-oxidase in generating oxidative burst necessary for inducing $\mathrm{ARF}^{10}$. Moreover, in the same experiment, exogenous application of $\mathrm{H}_{2} \mathrm{O}_{2}(20-40 \mathrm{mM})$ to the hypocotyl explants, after removal of primary roots significantly improved the number of ARs per explant (number, $P<0.05)$, while treatment with a different doses of $\mathrm{H}_{2} \mathrm{O}_{2}(10-50 \mathrm{mM})$ augmented the biomass of AR developed from each hypocotyl explant of cucumber compared to untreated control, indicating the dose-dependent nature of $\mathrm{H}_{2} \mathrm{O}_{2}$ on ARF and growth ${ }^{10}$. Further experiments with higher doses of $\mathrm{H}_{2} \mathrm{O}_{2}(1-100 \mathrm{mM})$ showed significant impact on both biomass and number of adventitious roots $^{11}$

Experimental evidences suggest that application of IAA can mimic the effect of $\mathrm{H}_{2} \mathrm{O}_{2}$ on ARF, through its 


\section{REVIEW ARTICLES}

up-regulatory impact on the number of $\mathrm{ARs}^{10}$. Significantly, IAA application had less or no impact on the biomass of adventitious roots as that of $\mathrm{H}_{2} \mathrm{O}_{2}$ (ref. 10). Catalase and ascorbic acid $(2 \mathrm{mM})$, when applied exogenously, showed no impact on ARF, but eliminated or suppressed the stimulatory role of exogenous $\mathrm{H}_{2} \mathrm{O}_{2}$ by eliminating it from the treatment solution. However, the application of $4 \mathrm{mM}$ ascorbic acid drastically reversed the ARF augmented by application of exogenous IAA or $\mathrm{H}_{2} \mathrm{O}_{2}$ (ref. 55). Treatment with $4 \mathrm{mM}$ ascorbic acid followed by $2.5 \mathrm{mM} \mathrm{H}_{2} \mathrm{O}_{2}$ for three days inhibited the elongation of adventitious roots to some extent ${ }^{55}$. Application of higher doses of DPI ( $5 \mathrm{mM})$ to the hypocotyl explants of cucumber, inhibits the effect of exogenous $\mathrm{H}_{2} \mathrm{O}_{2}$ on the promotion of $A R F$, indicating that apart from $\mathrm{NAD}(\mathrm{P}) \mathrm{H}-$ oxidase, some flavin-dependent enzymes are also inhibited by elevated concentrations of DPI ${ }^{10}$. In sweet-potato seedlings, exogenous application of $\mathrm{H}_{2} \mathrm{O}_{2}$ at low concentration (0.5 mM), significantly enhances ARF (assessed in terms of root weight, root number, root length and total surface area per plant). However, higher concentration of $\mathrm{H}_{2} \mathrm{O}_{2}$ inhibited ARF, suggesting the significance of threshold concentration of $\mathrm{H}_{2} \mathrm{O}_{2}$ in $\mathrm{ARF}^{55}$. Hydrogen peroxide treatments also increased total soluble sugar level indicating a signalling pathway that regulate division and differentiation of cells, leading to the formation of new root primordium $^{36}$.

\section{Molecular regulation of adventitious root formation involving reactive oxygen species}

In auxin-mediated ARF, application of a bacterial quora signal molecule, 3-O-C10-HL ( $N$-3-oxo-decanoylhomoserine-lactane) induced rapid accumulation of $\mathrm{H}_{2} \mathrm{O}_{2}$ along with NO. This in turn, activated transcription factors for several cell-cycle regulatory gene, like calciumdependent protein kinase (CDPK), cell division control protein 2 (CDC2), auxin-regulated protein $\mathrm{C}(\mathrm{ARC})^{56}$. All these genes are accountable for the regulation of cell cycle and cell division ${ }^{56}$. In cucumber, QTL mapping of AR developed under waterlogging stress has shown that ARF is regulated and inherited by a pair of negative dominance major genes (ARN6.1) and additive minor polygene (ARN3.1 and ARN5.1) (D-4 model) ${ }^{56}$. Another study has revealed that $A R N 6.1$ is governed by many candidate genes like ethylene responsive genes (Csa6G503880, Csa6G504590) which encode CPY (cytochrome P450 monooxygenase) that is involved in cell growth, and heavy metal homeostasis gene (Csa6G500660) encoding heavy metal-associated protein ${ }^{57}$ (Figure 6).

In growing roots of Arabidopsis, a separate and distinct zone of accumulation of superoxide anion and hydrogen peroxide was noticed. The accumulation is largely regulated by bHLH (a transcription factor UPBEAT1), which down-regulates specific peroxidase gene ${ }^{58,59}$. Transcrip- tomic studies involving RNA-Seq and qRT-PCR techniques were used in $\mathrm{H}_{2} \mathrm{O}_{2}$-treated seedling explants of mung bean for analysis of changes in global gene expression along with their functional annotations. Further, GO and KEGG pathway enrichment analyses have identified a major alteration in gene function after $6 \mathrm{~h}$ of $\mathrm{H}_{2} \mathrm{O}_{2}$ treatment ${ }^{60} \cdot \mathrm{H}_{2} \mathrm{O}_{2}$ treatment clearly exhibited temporal changes in the pattern of expression levels of ARFrelated genes, showing an upregulation in expression levels at $6 \mathrm{~h}$ of treatment and down-regulation at $24 \mathrm{~h}$ of treatment compared to control (water treatment) ${ }^{60}$. The upregulated genes that have been identified at $6 \mathrm{~h}$ of treatment (database of essential genes, DEG) found to be mostly involved in stress responses and includes small molecular weight HSP-like genes, a germin-like protein, extensin class-1 protein, a molecular chaperone regulator 6-like gene (BAG family) and a multiprotein-bridging

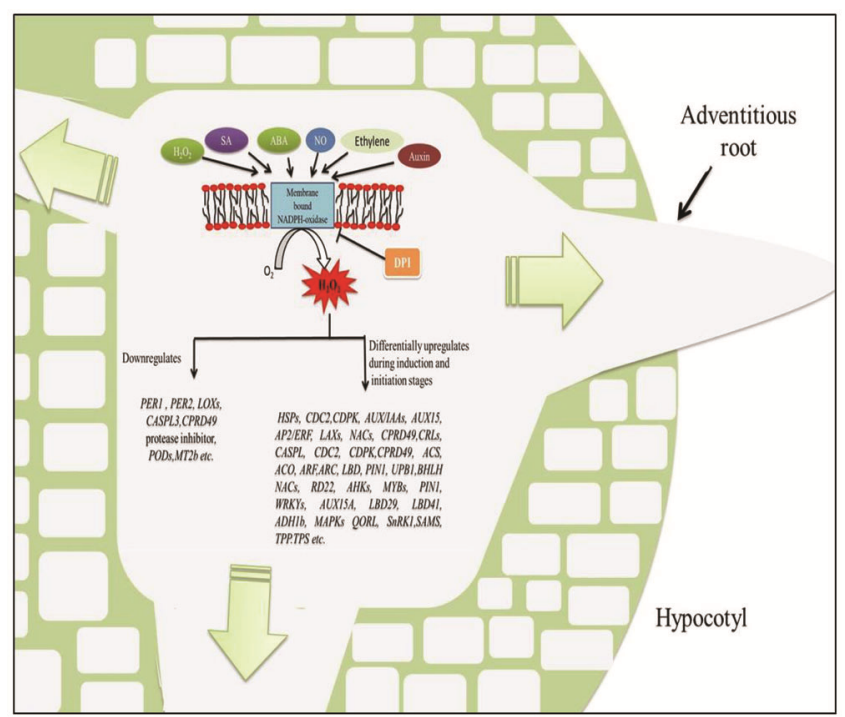

Figure 6. PGR-ROS or ROS-antioxidant interactions regulate redox status of plants necessary for the expression of various transcription factors and proteins that are involved in stress response, cell division, cell-wall modification and several metabolic pathways necessary for ARF. $A C O-1$, Aminocyclopropane-1-carboxylate oxidase; $A C S-1$, Aminocyclopropane-1-carboxylate synthase; $A P 2 / E R F$, AP2-like ethylene responsive transcription factor; $A D H 1 b$, Alcohol dehydrogenase; AHKs, His-protein kinase; $A R C$, Auxin regulated protein $\mathrm{C} ; A R F$, Auxin response factor; $A U X / I A A s$, Auxin proteins; $A U X 15$, Auxin early responsive 15 gene; BHLH, Basic helix-loop-helix protein; CASPL, Casparian strip membrane proteins; $C D C 2$, Cell division control protein 2; CDPK, Calcium-dependent protein kinase; CPRD49, Cowpea clones responsive to dehydration like genes; $C R L, C R O W N$ ROOTLESS; HSPs, Heat shock proteins; LAX, Auxin transport-like protein; LBD, Lateral organ boundaries domain TFs; LOXs, Lipoxygenase; MAPKs, Mitogen-activated protein kinase; $M T 2 b$, METALLOTHIONEIN2b; MYBs, Myeloblastosis TFs; NACs, NAM; $A T A F$ and $C U C$ family genes; PERI and 2, Cationic peroxidase; PIN1, PIN-formed protein genes; PODs, Peroxidase genes; $Q Q R L$, Quinone oxidoreducatse-like protein; $R D 22$, Response to dehydration 22 gene; $S A M S, S$-adenosylmethionine synthase; $S n R K 1$, Sucrose non-fermenting 1-related protein kinase; TPP, Trehalose-6-phosphate phosphatase; TPS, Trehalose-6-phosphate synthase; WRKYs, Pathogenesis-related genes and UPB1, UPBEAT1. 
factor 1c-like protein ${ }^{60}$. The temporal changes in $\mathrm{H}_{2} \mathrm{O}_{2}$ induced gene expression were also evident when the number of DEGs at 6 and $24 \mathrm{~h}$ of treatment $(29.9 \%$ higher in $6 \mathrm{~h}$-treated explants compared to $24 \mathrm{~h}$ treated one) were compared $^{60}$. Both DEG analysis and qRT-PCR results showed that $\mathrm{H}_{2} \mathrm{O}_{2}$ treatment significantly altered the expression levels of several genes like $A R F s$, IAAs, $A U X s, N A C s, R D 22, A P 2 / E R F s, A H K s, M Y B s$, PIN1, AUX15A, LBD29, LBD41, ADH1b, GH3, HSPs, HSFs, $Q O R L$ and genes of a variety of proteins and transcription factors. These ROS-induced differentially expressed (upregulated) genes are primarily involved in chemical modification of cell wall, cell division, redox regulation, acclamatory stress response, auxin and ethylene physiology, amino acid synthesis, protein processing and hormone signalling ${ }^{60}$. However, the differential regulations of these genes were variable in 6 and $24 \mathrm{~h} \mathrm{H}_{2} \mathrm{O}_{2}$ treatment conditions. On the contrary, PER1, PER2, CASPL3, $C P R D 49$ protease inhibitor, $L O X S$, PODs, antioxidant activity, and various pathways related to protein degradation, photosynthesis, cellular respiration, flavonoid synthesis, lipid transport and metabolism were downregulated in these treatments ${ }^{60}$.

Transcriptome analysis in $\mathrm{H}_{2} \mathrm{O}_{2}$-treated seedling explants of Petunia hybrida also showed the possible involvement of genes that are largely associated with metabolic regulations ${ }^{61}$. The transcripts that exhibited an upregulatory trend included genes responsible for lipid metabolism (beta oxidation), trehalose metabolism (TPP and TPS), loading and unloading of photosynthates (sucrose), acquisition of mineral nutrients, sucrose nonfermenting 1-related protein kinase (SnRK1) and Sadenosylmethionine synthase (SAMS) ${ }^{61}$. Zhang et al. ${ }^{62}$ reported that four out of 18 genes that are upregulated under $\mathrm{H}_{2} \mathrm{O}_{2}$ treatment in explants of poplar seedlings during ARF are associated with redox regulation primarily involving peroxidases, indicating redox regulation of AR development. Changes in activities of peroxidases and their isoform patterns (isozymes) have been projected as molecular markers of succeeding phases of the development of AR along with their implication in other important life processes like regulation of cell expansion, cell-wall lignification, auxin metabolism, etc. ${ }^{63}$. This finding suggests the imperative role of peroxidaseinduced redox regulation at later stages of ARF, when auxin becomes inhibitory to ARF. CRL1 and CRL3 (CROWN ROOTLESS) were shown to encode a positive regulator for ARF under auxin signalling pathway during initiation stage ${ }^{63}$ (Figure 6). $\mathrm{H}_{2} \mathrm{O}_{2}$ also induced responses to various abiotic and biotic stresses through MAPKsignal transduction pathway ${ }^{63}$.

RNA-Seq-based transcriptome analysis in poplar has revealed that highest numbers of differential expressed genes are found between 0 and 2 days after excision, indicating this stage is crucial for $\mathrm{ARF}^{62}$. When phytohormones-related genes were studied, more than 800 genes were envisaged to be involved in the synthesis, movement, metabolism and signalling of phytohormones like ABA, IAA, BRs, SA, ET, GA, CK and JA. Further, each gene exhibited additional related genes, of which auxin and BRs positively regulated $\mathrm{ARF}^{62}$. The BRs, cytokinins and SA metabolism genes were also found to have elevated expression from DAE2 to DAE8. The differential expressed genes in poplar were grouped into five clusters and all the clusters showed unique expression patterns. KEGG analysis showed that the peroxidase (responsible for redox homeostasis) pathway was enriched in cluster 6. Also, genes in these clusters showed upregulation from DAE 2 to DAE $8 . \mathrm{H}_{2} \mathrm{O}_{2}$ was shown to gradually increase from DAE0 to DAE8 (ref. 62).

Some important contemporary transcriptomic studies have explored gene ontology, KEGG pathway enrichment, and profiling of differentially expression genes. They showed that redox gateway is primarily involved in triggering ARF through the regulation of important cellular activities like acclamatory stress response, secondary metabolism, loosening and modification of cell wall, modulating nutrients and energy metabolism, movement sub-cellular components, protein metabolites, DNA replication, cell cycle and regulating gene expression associated with hormonal signalling pathways ${ }^{62}$. EST (expressed sequence tag) study was also explored for identifying transcripts involved in $\mathrm{ARF}^{64}$. That the ROS pathway is significantly involved in ARF could also be consolidated by gene expression cluster analysis ${ }^{3}$. Some studies also provide a record of candidate genes that are specifically regulated by redox cue during ARF in plants (Table 1).

\section{Conclusion and perspectives}

The article describes redox gateway as the primary regulator of ARF in plants under the influence of both abiotic environmental stress and endogenous growth factors. Almost every growth regulator such as auxin, ethylene, abscisic acid, NO, SA, etc. exploits the oxidative burst for ARF. ROS interact with different molecules formed during stress conditions to bring about morphological and anatomical changes necessary for ARF. Transcriptomic analysis revealed several differentially expressed genes that are upregulated and down-regulated in the hormonal signalling pathway where $\mathrm{H}_{2} \mathrm{O}_{2}$ acts as secondary messenger during ARF. Moreover, due to abiotic stress (drought, flood), or removal of primary roots, whether by cutting or physical damage, different hormones and signalling intermediates have been shown to enhance ROS formation through upregulation of RBOH genes. Subsequently, ROS acting in the downstream initiate or activate various transcription factors associated with cell division, cell-wall slackening, trehalose metabolism, mineral nutrients acquisition and beta oxidation pathway, 


\section{REVIEW ARTICLES}

Table 1. Genes influenced (primarily upregulated) by redox cue $\left(\mathrm{H}_{2} \mathrm{O}_{2}\right.$ priming) during different phases of adventitious root formation (ARF) in plants

\begin{tabular}{|c|c|c|c|}
\hline Genes upregulated & Redox cue & Functions & Reference \\
\hline WRKY, NAC, bZip, $N A C, M y b, Z F$ & $\begin{array}{l}\mathrm{H}_{2} \mathrm{O}_{2} \text {-induced upregulation during initiation and } \\
\text { progression phases of ARF }\end{array}$ & $\begin{array}{l}\text { Transcription factors of different } \\
\text { cell signalling episodes associated } \\
\text { with morphogenesis }\end{array}$ & 60,64 \\
\hline AUX/IAA, $A R F, G H 3, P I N 1$, ABP & $\begin{array}{l}\mathrm{H}_{2} \mathrm{O}_{2} \text {-induced upregulation during initiation and } \\
\text { progression phases of ARF }\end{array}$ & $\begin{array}{l}\text { Auxin signalling associated with } \\
\text { ARF }\end{array}$ & $3,60,65$ \\
\hline $\begin{array}{l}\text { Cytokinin dehydrogenase } 2, \\
\text { cytokinin riboside } \\
\text { monophosphate } \\
\text { phosphoribohydrolase, } L O G 1\end{array}$ & $\begin{array}{l}\mathrm{H}_{2} \mathrm{O}_{2} \text {-induced upregulation during initiation and } \\
\text { progression phases of ARF }\end{array}$ & $\begin{array}{l}\text { Cytokinin-induced message during } \\
\text { ARF }\end{array}$ & 39,60 \\
\hline$A C O, A S, E R F, A P 2$ & $\begin{array}{l}\mathrm{H}_{2} \mathrm{O}_{2} \text {-induced upregulation during initiation and } \\
\text { progression phases of ARF }\end{array}$ & $\begin{array}{l}\text { Ethylene signalling associated with } \\
\text { ARF }\end{array}$ & 39,60 \\
\hline $\begin{array}{l}\text { STOP1, cyst-rich receptor, prol-rich } \\
\text { prot kinase, Rec-like prot } \\
\text { kinase } 2\end{array}$ & $\begin{array}{l}\mathrm{H}_{2} \mathrm{O}_{2} \text {-induced upregulation during initiation and } \\
\text { progression phases of ARF }\end{array}$ & $\begin{array}{l}\text { Signal transduction intermediate/ } \\
\text { proteins associated with ARF }\end{array}$ & $39,60,66$ \\
\hline $\begin{array}{l}\text { Expansin B1, pectin esterase, } \\
\text { endoglucanase }\end{array}$ & $\begin{array}{l}\mathrm{H}_{2} \mathrm{O}_{2} \text {-induced upregulation during initiation and } \\
\text { progression phases of ARF }\end{array}$ & $\begin{array}{l}\text { Cell-wall modification associated } \\
\text { with ARF }\end{array}$ & $39,60,66$ \\
\hline$A P O X, D H A R, G R, C A T$ & $\begin{array}{l}\mathrm{H}_{2} \mathrm{O}_{2} \text {-induced upregulation during initiation and } \\
\text { progression phases of ARF }\end{array}$ & $\begin{array}{l}\text { Antioxidant coupled redox } \\
\text { signalling associated with ARF }\end{array}$ & 12,60 \\
\hline $\begin{array}{l}\text { Small molecular weight HSPs, } \\
\text { Class I, II, IV HSPs }\end{array}$ & $\begin{array}{l}\mathrm{H}_{2} \mathrm{O}_{2} \text {-induced upregulation during initiation and } \\
\text { progression phases of ARF }\end{array}$ & $\begin{array}{l}\text { HSP chaperone function, Stability of } \\
\text { proteins necessary for ARF }\end{array}$ & 65,66 \\
\hline
\end{tabular}

sucrose unloading processes. These events ultimately leading to morphological changes like ARF, which is indispensible for enhancing water and nutrients uptake from the surroundings during stress for survival. The redox manipulation of tissues through down-regulation of ROS-generating enzymes like NAD(P)H-oxidase $(\mathrm{RBOH})$ through exogenous application of DPI or other radical scavengers like DMTU significantly alters ARF, again substantiating the role of endogenous redox cue during ARF. All these results conclusively show that ROS are important and act downstream of many phytohormones as the gateway in initiating ARF. The mechanism of ROS signalling cascade resulting in morphological changes is still unexplored and further work must be done to understand this underlying mechanism. The understanding of redox biology associated with this developmental process can help in vegetative propagation of various plants and recalcitrant species. Further, exploring 'omic' technologies for understanding the molecular language along with monitoring spatio-temporal hormonal modulation and histochemical observations using confocal microscopy, could help decipher the exact role of redox regulation in integrating diverse signalling processes that culminate into a developmental process.

1. Bellini, C., Pacurar, D. I. and Perrone, I., Adventitious roots and lateral roots: similarities and differences. Annu. Rev. Plant Biol., 2014, 65, 639-666.

2. Massoumi, M., Adventitious root formation in Arabidopsis thaliana: development of a model system. Acta Hortic., 2016, 988, 99105 .

3. Steffens, B. and Rasmussen, A., The physiology of adventitious roots. Plant Physiol., 2016, 170, 603-617.
4. DeKlerk, G. J., Krieken, W. V. D. and Jong, J., The formation of adventitious roots: new concepts, new possibilities. In Vitro Cell Dev. Biol., 1999, 35, 189-199.

5. Lorbiecke, R. and Sauter, M., Adventitious root growth and cellcycle induction in deepwater rice. Plant Physiol., 1999, 119, 21-30.

6. Visser, E., Cohen, J. D., Barendse, G., Blom, C. and Voesenek, L., An ethylene-mediated increase in sensitivity to auxin induces adventitious root formation in flooded Rumex palustris Sm. Plant Physiol., 1996, 112, 1687-1692.

7. Steffens, B., The role of ethylene and ROS in salinity, heavy metal, and flooding responses in rice. Front. Plant Sci., 2014, 5, 685.

8. Potters, X. G., Pasternak, T. P., Guisez, Y. and Jansen, M. A. K., Different stresses, similar morphogenic responses: integrating a plethora of pathways. Plant Cell Environ., 2009, 32, 158-169.

9. Strubińska, J. and Hanaka, A., Adventitious root system reduces lead uptake and oxidative stress in sunflower seedlings. Biol. Plant., 2011, 55(4), 771-774.

10. Li, S., Xue, L., Xu, S., Feng, H. and An, L., Hydrogen peroxide involvement in formation and development of adventitious roots in cucumber. Plant Growth Regul., 2007, 52, 173-180.

11. Li, S. W., Xue, L., Xu, S., Feng, H. and An, L., Hydrogen peroxide acts as a signal molecule in the adventitious root formation of mung bean seedlings. Environ. Exp. Bot., 2009, 65(1), 6371.

12. Kora, D. and Bhattacharjee, S., The interaction of reactive oxygen species and antioxidants at the metabolic interface in salicylic acid-induced adventitious root formation in mung bean [Vigna radiata (L.) R. Wilczek]. J. Plant Physiol., 2020; https://doi.org/ 10.1016/j.jplph.2020.153152

13. Bhattacharjee, S., The language of reactive oxygen species signaling in plants. J. Bot., 2012, 985298, 22.

14. Torres, M. A. and Dangel, J. L., Functions of the respiratory burst oxidase in biotic interactions, abiotic stress and development. Curr. Opin. Plant Biol., 2005, 8(4), 397-403.

15. Yamauchi, T. et al., Ethylene and reactive oxygen species are involved in root aerenchyma formation and adaptation of wheat seedlings to oxygen-deficient conditions. J. Exp. Bot., 2014, 65, 1, 261-273. 
16. Yamauchi, T. et al., An NADPH oxidase RBOH functions in rice roots during lysigenous aerenchyma formation under oxygendeficient conditions. Plant Cell, 2017, 29(4), 775-790.

17. Lambeth, J. D., NOX enzymes and the biology of reactive oxygen Nature Rev. Immunol., 2004, 4(3), 181-189.

18. Sagi, M. and Fluhr, R., Production of reactive oxygen species by plant NADPH oxidases. Plant Physiol., 2006, 141(2), 336340.

19. Sagi, M. and Fluhr, R., Superoxide production by plant homologues of the gp91(phox) NADPH oxidase. Modulation of activity by calcium and by tobacco mosaic virus infection. Plant Physiol., 2001, 126, 1281-1290.

20. Simon-Plas, F., Elmayan, T. and Blein, J. P., The plasma membrane oxidase NtrbohD is responsible for AOS production in elicited tobacco cells. Plant J., 2002, 31, 137-147.

21. Apel, K. and Hirt, H., Reactive oxygen species: Metabolism oxidative stress and signal transduction. Annu. Rev. Plant Biol., 2004, 55, 373-399.

22. Asada, K., Production and scavenging of reactive oxygen species in chloroplasts and their functions. Plant Physiol., 2006, 141, 391-396.

23. Qi, X. et al., Water logging-induced adventitious root formation in cucumber is regulated by ethylene and auxin through reactive oxygen species signaling. Plant Cell Environ., 2018, 42(5), 14581470 .

24. Steffens, B., Kovalev, A., Gorb, S. N. and Sauter, M., Emerging roots alter epidermal cell fate through mechanical and reactive oxygen species signaling. Plant Cell, 2012, 24(8), 3296-3306.

25. Neill, S. J., Desikan, R., Clarke, A., Hurst, R. D. and Hancock, J. $\mathrm{T}$., Hydrogen peroxide and nitric oxide as signaling molecule in plants. J. Exp. Biol., 2002, 53, 1237-1247.

26. Baxter-Burrell, A., Yang, Z., Springer, P. S. and Bailey-Serres, J., RopGAP4-dependent Rop GTPase rheostat control of Arabidopsis oxygen deprivation tolerance. Science, 2002, 296, 2026-2028.

27. Wong, H. L. et al., Regulation of rice NADPH oxidase by binding of rac GTPase to its $N$-terminal extension. Plant Cell, 2007, 19, 4022-4034.

28. Steffens, B., Sauter, M. and Steffens-Heins, A., Reactive oxygen species mediate growth and death in submerged plants published. Plant Sci., 2013, 4, 179.

29. Liao, W. B., Xiao, H. L. and Zhang, M. L., Nitric oxide and hydrogen peroxide alleviate drought stress in marigold explants and promote its adventitious root development. Plant Physiol. Biochem., 2012, 58, 6-15.

30. Mergemann, H. and Sauter, M., Ethylene induces epidermal cell death at the site of adventitious root emergence in rice. Plant Physiol., 2002, 124, 609-614.

31. Steffens, B. and Sauter, M., Epidermal cell death in rice is confined to cells with a distinct molecular identity and is mediated by ethylene and $\mathrm{H}_{2} \mathrm{O}_{2}$ through an auto amplified signal pathway. Plant Cell, 2009, 21, 184-196.

32. Quan, L. J., Zhang, B., Shi, W. W. and Li, H. Y., Hydrogen peroxide in plants: a versatile molecule of the reactive oxygen species network. J. Integr. Plant Biol., 2008, 50, 2-18.

33. Guan, L., Murphy, A. S., Peer, W. A., Gan, L., Li, Y. and ZongMing (Max) Cheng, Physiological and molecular regulation of adventitious root formation. Plant Sci., 2015, 34(5), 506-521.

34. Wong, H. L., Sakamoto, T., Kawasaki, T., Umemura, K. and Shimamoto, K., Down-regulation of metallothionein, a reactive oxygen scavenger, by the small GTPase OsRac1 in rice. Plant Physiol., 2004, 135, 1447-1456.

35. Liao, W. B., Xiao, H. L. and Zhang, M. L., Nitric oxide and hydrogen peroxide are involved in indole-3-butyric acid-induced adventitious root development in marigold. J. Hortic. Sci. Biotechnol., 2011, 86(2), 159-165.

36. Liao, W. B., Xiao, H. L. and Zhang, M. L., Effect of nitric oxide and hydrogen peroxide on adventitious root development from cuttings of ground-cover Chrysanthemum and associated biochemical changes. J. Plant Growth Regul., 2010, 29, 338-348.

37. Tewari, R. K., Hahn, E. J. and Paek, K. Y., Function of nitric oxide and superoxide anion in the adventitious root development and antioxidant defence in Panax ginseng. Plant Cell Rep., 2008, 27, 563-573.

38. Kushwaha, B. K. et al., New adventitious root formation and primary root biomass accumulation are regulated by nitric oxide and reactive oxygen species in rice seedlings under arsenate stress. $J$. Hazard. Mater., 2018, 361, 134-140.

39. Li, X. P. et al., Hydrogen peroxide is involved in abscisic acidinduced adventitious rooting in cucumber (Cucumis sativus L.) under drought stress. J. Plant Biol., 2016, 59, 536-548.

40. Takac, T., Obert, B., Rolck, J. and Samaj, J., Improvement of adventitious root formation in flax using hydrogen peroxide. New Biotechnol., 2016, 33(5), 728-734.

41. Li, M. Y., Cao, Z. Y., Shen, W. B. and Cui, J., Molecular cloning and expression of a cucumber (Cucumis sativus L.) heme oxygenase-1 gene, CsHO1, which is involved in adventitious root formation. Gene, 2011, 486, 47-55.

42. Yang, W., Zhu, C., Ma, X., Li, G., Gan, L., Ng, D. and Xia, K., Hydrogen peroxide is a second messenger in the salicylic acidtriggered adventitious rooting process in mung bean seedlings. PLoS ONE, 2013, 8, 12.

43. Gutierrez, L. et al., Auxin controls Arabidopsis adventitious root initiation by regulating jasmonic acid homeostasis. Plant Cell, 2012, 24(6), 2515-2527.

44. Rogers, E. E. and Ausubel, F. M., Arabidopsis enhanced disease susceptibility mutants exhibit enhanced susceptibility to several bacterial pathogens and alterations in PR-1 gene expression. Plant Cell, 1997, 9(3), 305-316.

45. Wasternack, C. et al., The wound response in tomato: role of jasmonic acid. J. Plant Physiol., 2006, 163, 297-306.

46. Orozco-Cárdenas, M. L. and Ryan, C., Hydrogen peroxide is generated systemically in plant leaves by wounding and systemin via the octadecanoid pathway. Proc. Natl. Acad. Sci. USA, 1999, 96, 6553-6557.

47. Orozco-Cárdenas, M. L., Narváez-Vásquez, J. and Ryan, C. A., Hydrogen peroxide acts as a second messenger for the induction of defense genes in tomato plants in response to wounding, systemin, and methyl jasmonate. Plant Cell, 2001, 13, 179-191.

48. Santos Macedo, E. et al., Physiologic responses and gene diversity indicate olive alternative oxidase as a potential source for markers involved in efficient adventitious root induction. Physiol. Plant, 2009, 137, 532-552.

49. She, X. P., Huang, A. X. and Ren, Y., Hydrogen peroxide generated by copper amine oxidase involved in adventitious root formation in mung bean hypocotyl cutting. J. Bot., 2010, 58, 656-662.

50. Li, S. W. and Xue, L. G., The interaction between $\mathrm{H}_{2} \mathrm{O}_{2}$ and NO, $\mathrm{Ca}^{2+}$, cGMP, and MAPKs during adventitious rooting in mung bean seedlings. In Vitro Cell Dev. Biol. - Plant, 2010, 46, 142-148.

51. Jaleel, C. et al., Antioxidant defense responses: physiological plasticity in higher plants under abiotic constraints. Acta Physiol. Plant., 2009, 31, 427-436.

52. Singh, H. P., Kaur, S., Batish, D. R. and Kohli, R. K., Caffeic acid inhibits in vitro rooting in mung bean [Vigna radiata (L.) Wilczek] hypocotyls by inducing oxidative stress. Plant Growth Regul., 2008, 57, 21-30.

53. Tian, N., Liu, S., Li, J., Xu, W., Yuan, L., Huang, J. and Liu, Z., Metabolic analysis of the increased adventitious rooting mutant of Artemisia annua reveals a role for the plant monoterpene borneol in adventitious root formation. Physiol. Plant., 2014, 151(4), 522532.

54. Guo, Y., Wu, Q., Xie, Z., Yu, B., Zeng, R., Min, Q. and Huang, J., OsFPFL4 is involved in the root and flower development by affecting auxin levels and ROS accumulation in rice (Oryza sativa). Rice, 2020, 13(2). 
55. Deng, X. P., Cheng, Y. J., Wu, X. B., Kwak, S. S., Chen, W. and Eneji, A. E., Exogenous hydrogen peroxide positively influences root growth and metabolism in leaves of sweet potato seedlings. Aust. J. Crop Sci., 2012, 6(11), 1572-1578.

56. Bai, X., Todd, C. D., Desikan, R., Yang, Y. and Hu, X., N-3oxo-decanoyl-L-homoserine-lactone activates auxin-induced adventitious root formation via hydrogen peroxide- and nitric oxide-dependent cyclic GMP signaling in mung bean. Plant Physiol., 2012, 158(2), 725-736.

57. Xu, X., Ji, J., Xu, Q., Qi, X. and Chen, X., Inheritance and quantitative trail loci mapping of adventitious root numbers in cucumber seedlings under waterlogging conditions. Mol. Genet. Genomics, 2016, 292, 353-364.

58. Tsukagoshi, H., Busch, W. and Benfey, P. N., Transcriptional regulation of ROS controls transition from proliferation to differentiation in the root. Cell, 2010, 143, 606-616.

59. Dunand, C., Crevecoeur, M. and Penel, C., Distribution of superoxide and hydrogen peroxide in Arabidopsis root and their influence on root development: possible interaction with peroxidases. New Phytol., 2007, 174, 332-341.

60. Li, S. W., Leng, Y. and Shi, R. F., Transcriptomic profiling provides molecular insights into hydrogen peroxide-induced adventitious rooting in mung bean seedlings. BMC Genomics, 2017, 18, 188 .

61. Ahkami, A. et al., Comprehensive transcriptome analysis unravels the existence of crucial genes regulating primary metabolism during adventitious root formation in Petunia hybrid. PLOS ONE, 2014, 9(6), e100997.

62. Zhang, Y., Xiao, Z., Zhan, C., Liu, M., Xia, W. and Wang, N., Comprehensive analysis of dynamic gene expression and investi- gation of the roles of hydrogen peroxide during adventitious rooting in poplar. BMC Plant Biol., 2019, 19, 99-107.

63. Liu, Y. and He, C., A review of redox signaling and the control of MAP kinase pathway in plants. Redox Biol., 2017, 11, 192-204.

64. Li, K. et al., Transcriptome analysis reveals multiple hormones, wounding and sugar, signaling pathways mediate adventitious root formation in apple rootstock. Int. J. Mol. Sci., 2018, 19, 8-17.

65. Druege, U., Franken, P., Lischewski, S., Ahkami, A. H., Zerche, S., Hause, B. and Hajirezaei, M. R., Transcriptomic analysis reveals ethylene as stimulator and auxin as regulator of adventitious root formation in petunia cuttings. Front. Plant Sci., 2014, 5, 494-509.

66. Li, Y.-H., Zou, M.-H., Feng, B.-H., Huang, X., Zhang, Z. and Sun, G.-M., Molecular cloning and characterization of the genes encoding an auxin efflux carrier and the auxin influx carriers associated with the adventitious root formation in mango (Mangifera indica L.) cotyledon segments. Plant Physiol. Biochem., 2012, 55, 33-42.

ACKNOWLEDGEMENTS. D.K. thanks the University Grants Commission (UGC), New Delhi, for Junior Research Fellowship (Joint CSIR-UGC). S.B. thanks UGC for research funds to the Department of Botany, University of Burdwan [No. F.5-13/012 (SAP-II)].

Received 19 May 2020; accepted 1 June 2020

doi: $10.18520 / \mathrm{cs} / \mathrm{v} 119 / \mathrm{i} 3 / 462-472$ 